\title{
GIS-based data model and tools for creating and managing two- dimensional cross sections
}

Timothy L. Whiteaker

University of Texas at Austin

Norm Jones

Brigham Young University - Provo, njones@byu.edu

Gil Strassberg

Alan Lemon

Doug Gallup

Follow this and additional works at: https://scholarsarchive.byu.edu/facpub

Part of the Geotechnical Engineering Commons

\section{Original Publication Citation}

Whiteaker, T., N. Jones, G. Strassberg, A. Lemon, D. Gallup, "GIS-based Data Model and Tools for Creating and Managing Two-Dimensional Cross Sections,"Computers and Geosciences, Vol 29, Feb 2012.

\section{BYU ScholarsArchive Citation}

Whiteaker, Timothy L.; Jones, Norm; Strassberg, Gil; Lemon, Alan; and Gallup, Doug, "GIS-based data model and tools for creating and managing two-dimensional cross sections" (2011). Faculty Publications. 4283.

https://scholarsarchive.byu.edu/facpub/4283

This Peer-Reviewed Article is brought to you for free and open access by BYU ScholarsArchive. It has been accepted for inclusion in Faculty Publications by an authorized administrator of BYU ScholarsArchive. For more information, please contact ellen_amatangelo@byu.edu. 


\title{
GIS-based data model and tools for creating and managing two-dimensional cross sections
}

\author{
Timothy L. Whiteaker ${ }^{\mathrm{a}, *}$, Norm Jones ${ }^{\mathrm{b}}$, Gil Strassberg ${ }^{\mathrm{c}}$, Alan Lemon ${ }^{\mathrm{c}}$, Doug Gallup ${ }^{\mathrm{c}}$ \\ ${ }^{a}$ The University of Texas at Austin, 1 University Station, MC R8000, Austin, TX 78712, USA \\ b Brigham Young University, 242L Clyde Building, Provo, UT 84602, USA \\ c Aquaveo, LLC. 3210N Canyon Road, Suite 300, Provo, UT 84604, USA
}

\section{A R T I C L E I N F O}

\section{Article history:}

Received 7 February 2011

Received in revised form

31 May 2011

Accepted 1 June 2011

Available online 29 June 2011

Keywords:

Geographic information systems

Cross sections

Subsurface characterization

Geologic modeling

\begin{abstract}
A B S T R A C T
While modern Geographic Information Systems (GIS) software is robust in handling maps and data in plan view, the software generally falls short when representing features in section view. Further complicating the issue is the fact that geologic cross sections are often drawn by connecting a series of wells together that do not fall along a single straight line. In this case, the $x$-axis of the cross section represents the distance along the set of individual lines connecting the series of wells, effectively "flattening out" the cross section along this path to create a view of the subsurface with which geologists often work in printed folios. Even 3D-enabled GIS cannot handle this type of cross section. A GIS data model and tools for creating and working with two-dimensional cross sections are presented. The data model and tools create a framework that can be applied using ESRI's ArcGIS software, enabling users to create, edit, manage, and print two-dimensional cross sections from within one of the most wellknown GIS software packages. The data model is a component of the arc hydro groundwater data model, which means all two-dimensional cross sections are inherently linked to other features in the hydrogeologic domain, including those represented by $x y z$ coordinates in real world space. Thus, the creation of two-dimensional cross sections can be guided by or completely driven from standard GIS data, and geologic interpretations established on two-dimensional cross sections can be translated back to real world coordinates to create three-dimensional features such as fence diagrams, giving GIS users the capacity to characterize the subsurface environment in a variety of integrated views that was not possible before. A case study for the Sacramento Regional Model in California demonstrates the application of the methodology in support of a regional groundwater management plan.
\end{abstract}

(c) 2011 Elsevier Ltd. All rights reserved.

\section{Introduction}

While modern Geographic Information Systems (GIS) software is robust in handling maps and data in plan view, the software generally falls short when representing features in section view. Further complicating the issue is the fact that geologic cross sections are often drawn by connecting a series of points on borehole log plots associated with boreholes that do not fall along a single straight line. In this case, the $x$-axis of the cross section represents the distance along the set of individual lines connecting the series of boreholes, effectively "flattening out" the cross section along this path to create a view of the subsurface with which geologists often work in printed folios. Even 3D-enabled GIS cannot handle this type of cross section.

\footnotetext{
* Corresponding author. Tel.: +1 512471 0570; fax: + 15124710072.

E-mail addresses: twhit@mail.utexas.edu (T.L. Whiteaker), njones@byu.edu (N. Jones), gstrassberg@aquaveo.com (G. Strassberg), alemon@aquaveo.com (A. Lemon),dgallup@aquaveo.com (D. Gallup).
}

This paper presents a GIS data model and tools for creating and working with two-dimensional cross sections. The data model and tools create a framework that can be applied using ESRI's ArcGIS software, enabling users to create, edit, manage, and print two-dimensional cross sections from within one of the most wellknown GIS software packages. The data model is a component of the Arc Hydro Groundwater data model, which means all twodimensional cross sections are inherently linked to other features in the hydrogeologic domain, including those represented by $x y z$ coordinates in real world space. This enables the creation of twodimensional cross sections to be guided by or completely driven from standard GIS data. Geologic interpretations established on two-dimensional cross sections can be translated back to real world coordinates to create three-dimensional features such as fence diagrams, giving GIS users the capacity to characterize the subsurface environment in a variety of integrated views that was not possible before. In this paper, strengths and weaknesses of the methodology are evaluated, and the benefits of linking the two-dimensional features to other GIS features through Arc Hydro relationships are highlighted with a case study for the Sacramento Valley in California. 


\section{Background}

Cross sections are a valuable tool used by geologists and engineers when making a site characterization for a study such as a groundwater modeling project. Cross sections often utilize limited information from borehole logs, geophysical data, faults, outcrops, etc., to depict a three-dimensional geologic domain that is largely unseen, and traditionally represent this domain on two-dimensional printed documents. Cross section data are often used to facilitate the construction of three-dimensional geologic models (Herbert et al., 1995; Kaufmann and Martin, 2008; Lemon and Jones, 2003; Ming et al., 2010; Tipper, 1976). As more professionals turn to GIS software to facilitate site characterization and data management, it becomes desirable to enable the visualization of geologic cross sections within a GIS. Several commercial software vendors and organizations have attempted to create this functionality with varying degrees of success (A-Prime Software, 2008; RockWare, 2010; Thoms, 2008). The innovative aspect of the work presented in this paper is the integration of two-dimensional cross sections with other features related to site characterization in the GIS. This is made possible using the Arc Hydro Groundwater data model (Strassberg et al., 2007, 2011).

A geographic data model is like a blueprint specifying how real world entities are represented in a GIS using tables of features with relationships that tie features together. The Arc Hydro Groundwater data model builds from the widely used Arc Hydro data model (Maidment, 2002) for surface water features, to not only describe the groundwater system but also link these features back to the surface water system. The data model includes several components to represent aquifers and wells/boreholes, threedimensional hydrogeologic models, temporal information, and data from simulation models. While the primary implementation of this data model is within ESRI's ArcGIS software environment, the data model itself is public domain and components of the data model could be implemented in other GIS software packages.

The Hydrostratigraphy component of the Arc Hydro Groundwater data model represents hydrogeologic units using twodimensional and three-dimensional features. This component includes a HydrogeologicUnit table that defines the hydrogeologic units represented in the GIS database. These units are visualized using a variety of GIS datasets such as polygons representing the areal extent of hydrogeologic units, surfaces representing the top and bottom of hydrogeologic units, volume elements, fence diagrams, and two-dimensional cross sections. The two-dimensional cross sections comprise several classes of features and are described in Section 3.

\section{Data model for two-dimensional cross sections}

A common method of creating geologic cross sections is to draw a vertical plot of borehole log data from a series of boreholes and interpolate the stratigraphy between the boreholes. Sometimes a vertical exaggeration is applied on the vertical axis of the cross section to improve readability. In plan view, the boreholes are connected with a section line, such that the distance along the section line corresponds to the distance along the horizontal axis in the cross section, $s$. Thus, the section line is the vehicle by which real world coordinates $(x, y, z)$ are translated to cross section coordinates $(s, z)$. Fig. 1 illustrates the relationship between a section line and a cross section.

In the Arc Hydro Groundwater data model, a given cross section is always linked to a SectionLine feature representing the section line of the cross section. Like all features in the Arc Hydro Groundwater data model, each SectionLine feature possesses its own HydroID, a unique identifier that is used as a key
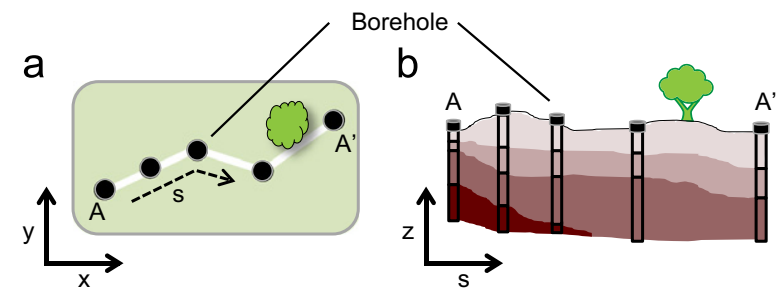

Fig. 1. Conceptual diagram of a section line and its associated cross section. (a) Plan view of section line $A-A^{\prime}$ connecting five boreholes. The view uses an $x y$ coordinate system such that $x$ represents longitude and $y$ represents latitude, for example. (b) Cross section $A-A^{\prime}$ in an $s z$ coordinate system where $s$ is the distance along the section line and $z$ is the elevation.

field when establishing relationships between features. The SectionLine feature class also includes an SName field for storing the name of the cross section (e.g., $A-A^{\prime}$ ) and a VertExag2D field for defining the vertical exaggeration to be used when displaying the cross section. The vertical exaggeration is applied to all cross section features related to a given section line.

The cross sections themselves comprise several feature classes representing the various elements that appear on printed cross sections, such as panels of hydrogeologic units and vertical segments representing boreholes. Features providing spatial reference such as horizontal and vertical grid lines are also provided. By storing all of these elements as GIS features (versus simple graphics), the full suite of GIS tools is available to operate on these elements, and they can be related back to other features in the GIS. The convention of prefixing the names of twodimensional cross section feature classes with "XS2D" is used to distinguish these $s z$ feature classes from the regular $x y z$ feature classes in the GIS. The core XS2D feature classes include XS2D_BoreLine, XS2D_Panel, XS2D_PanelDivider, XS2D_MajorGrid, and XS2D_MinorGrid. These features are shown in Fig. 2 and are described below. Additional feature classes can be added as necessary to represent features such as land surface elevation, outcrops, faults, water levels, and borehole construction.

Since the Arc Hydro Groundwater data model is designed in the context of groundwater studies, the borehole locations are identified using a Well point feature class. Each well point has a unique HydroID. Borehole log data and geophysical data are stored in separate tables that are related to wells using HydroIDs.

$X S 2 D \_$BoreLine is a polyline feature class representing vertical borehole data for a borehole pertinent to cross section. A given borehole will have one XS2D_Boreline feature for each stratigraphic layer (i.e., hydrogeologic unit for groundwater applications) that it penetrates. An XS2D_Boreline feature is attributed with WellID (the HydroID of its associated borehole), HGUID (the HydroID of its associated hydrogeologic unit), and attributes describing the hydrogeologic unit as observed in the well, e.g., TopElev for indicating the elevation of the top of the unit. Additional attributes for describing the position of the borehole with respect to the section line include Measure for indicating distance along the section line, Offset for indicating horizontal perpendicular distance away from the section line, and IsLeft indicating if the borehole falls on the left or right side of the section line as one traverses from the start to the end of the line. XS2D_Boreline features are used to guide the interpolation of cross section panels that span the area between boreholes.

$X S 2 D \_$Panel is a polygon feature class representing hydrogeologic units as two-dimensional cross section panels. An XS2D_Panel feature is attributed with the HydroID of the hydrogeologic unit that it represents. A given cross section will contain several XS2D_Panel features (one for each hydrogeologic unit present in the cross section). These features are typically created by 


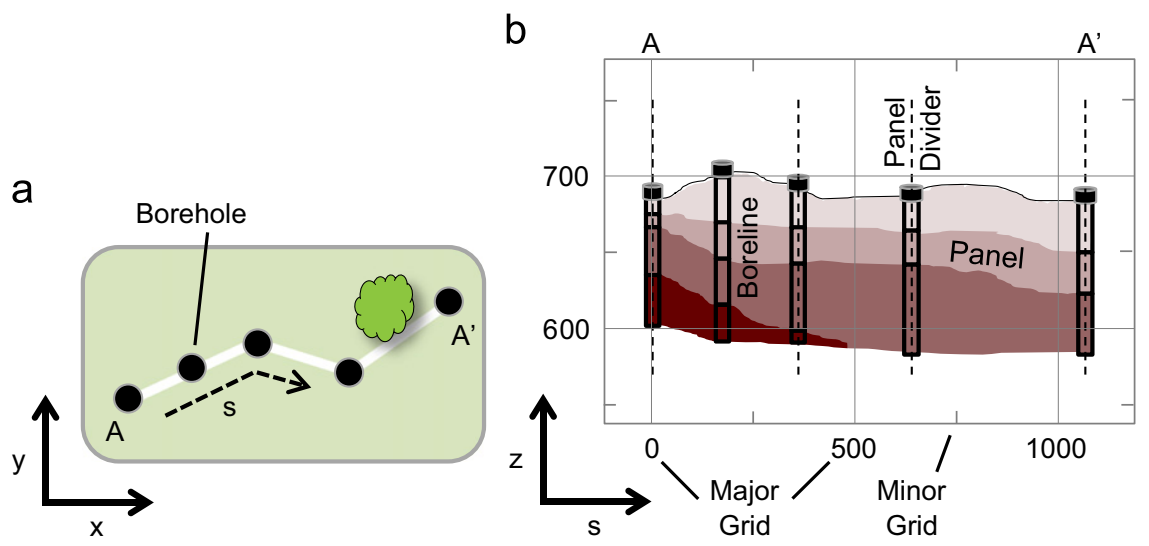

Fig. 2. Conceptual diagram of common cross section features.

interpolating from XS2D_Boreline data with additional input from features such as outcrops and known fault locations.

In many cases, the series of boreholes associated with a cross section do not lie along a single straight line in plan view. This results in interior vertices wherever the section line changes direction. XS2D_PanelDivider is a polyline feature class representing section line vertices as vertical lines on a cross section. In other words, panel dividers are drawn at the beginning and end of a cross section and in places where the section line changes direction. Each XS2D PanelDivider feature is attributed with a Measure field indicating the distance along the section line at which its associated vertex occurs. These panel divider features, along with major and minor grid lines, serve as a geospatial frame of reference for locating features along a cross section.

XS2D_MajorGrid and XS2D_MinorGrid are polyline feature classes representing horizontal and vertical grid lines on a cross section, which are used as guides for locating features in a cross section. Major grid lines are given more weight than minor grid lines when visualized. For example, major grid lines may appear across the entire cross section, while minor grid lines may be displayed merely as tick marks along the periphery of the cross section. Each vertical grid line is attributed with its distance along the section line, while each horizontal grid line is attributed with its elevation; these values are stored in the GridValue field. This becomes especially important when the cross section is scaled, because the horizontal grid lines will take into account the vertical exaggeration and will display the true elevation value. The grid lines are also attributed with an IsVertical field indicating if the grid line is vertical or horizontal.

A set of these XS2D feature classes is associated with a single section line, and each section line has its own set of XS2D feature classes. These associations are managed in the XS2D_Catalog table, where each row in the table includes a description of an XS2D feature class and information about its related SectionLine feature. Attributes of XS2D_Catalog include SectLineFc providing the name of the section line feature class, SectionID providing the HydrolD of the section line within the section line feature class, SName providing the name of the section, XS2D_FC providing the name of the XS2D feature class, and XS2DType indicating the type of XS2D feature that the XS2D feature class represents, e.g., panel. This structure allows any number of feature classes to be associated with a given cross section, and defines the role that each feature class plays in the cross section.

Fig. 3 shows a Unified Modeling Language diagram of cross section tables and feature classes in Arc Hydro. Additional diagrams and full details of the data model are described in Strassberg et al. (2011).
While the feature classes and tables described above can be stored using freely available open GIS data formats, the implementation in ESRI's ArcGIS software reveals the power of this data model as well as its limitations.

\section{Implementation in ArcGIS}

In ESRI's ArcGIS software, Arc Hydro Groundwater feature classes and tables are stored in the geodatabase format, which enables formal relationships between features and management of unique HydroIDs using the freely available Arc Hydro tools. The main difference between cross section features and more typical GIS features is that cross section features will not be assigned one of ArcGIS's standard coordinate systems since each cross section has a unique $s z$ coordinate system.

The challenging part of this implementation is the visualization of the cross sections. ArcGIS includes ArcMap for twodimensional mapping in plan view $(x, y)$, and ArcScene for visualization of three-dimensional features $(x, y, z)$. Neither of these environments directly supports the $s z$ coordinate system of cross sections. However, since the $s z$ system is a two-dimensional coordinate system, cross section features can be added to ArcMap and displayed as if they consisted of $x y$ data, where ArcMap's $x$-coordinate is really the $s$-coordinate of a cross section, and ArcMap's $y$-coordinate is really the $z$-coordinate of a cross section.

To help avoid inadvertently overlaying plan view $(x, y)$ data on cross sections, each cross section is displayed in its own ArcMap data frame, where a data frame is a container of map layers within an ArcMap document. Each data frame has its own unique coordinate system that is based on the length of the associated section line and the vertical exaggeration applied to cross section features. The user can toggle between data frames, and only one data frame is active at a time.

A complication arises when vertical scaling is desired for better visualization, as is typically the case for groundwater systems, which tend to be shallow in depth compared to their areal extent. ArcMap is not designed to display vertical exaggerations. Workarounds for this limitation have evolved such as map coordinate system manipulation described by Huber (2007). By defining the coordinate system of both the map and the cross section features as cylindrical equal area, the standard parallel of the map's coordinate system can be adjusted to render scaling in both the $x$ and $y$ directions, resulting in the appearance of vertical exaggeration. However, because the amount of scaling is not stored with the data, careful tracking of optimal vertical exaggeration is required when sharing the data. Additionally, 


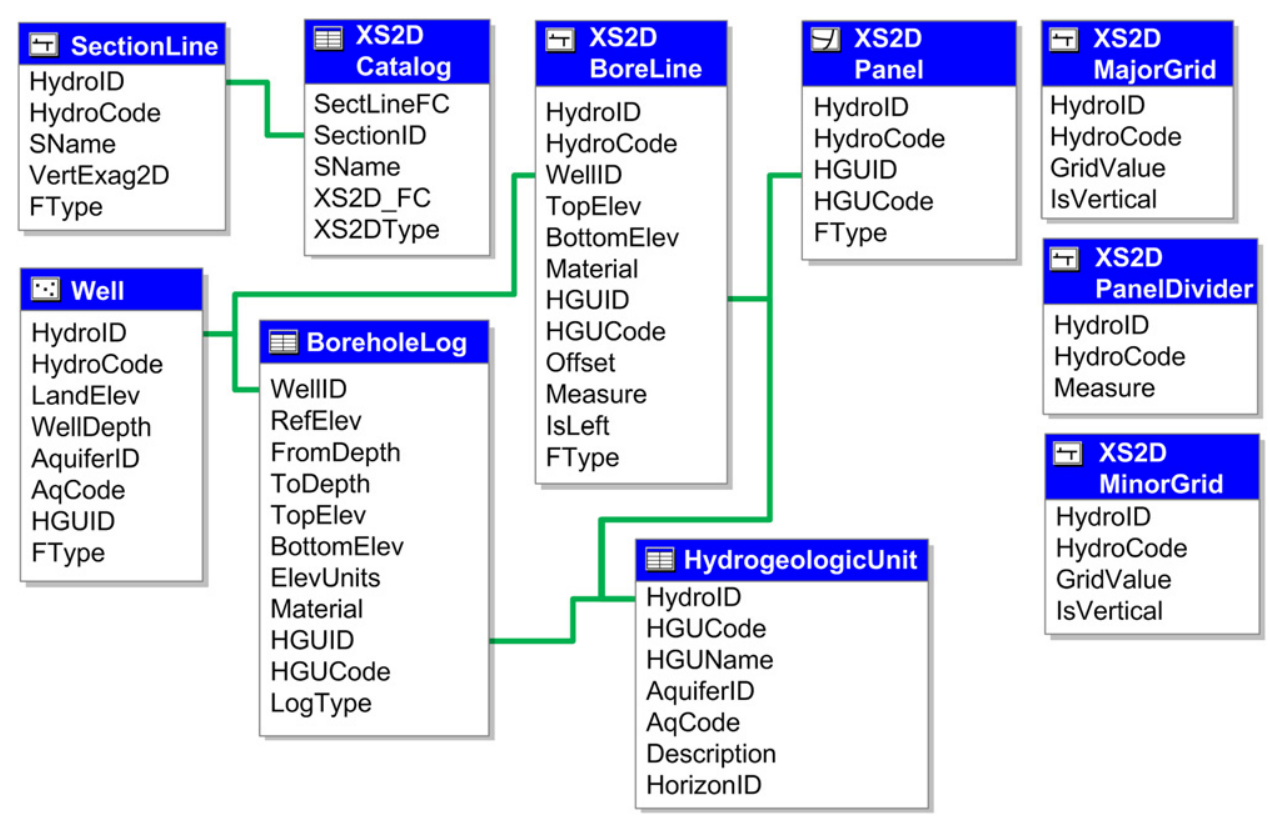

Fig. 3. Simplified UML class diagram showing key attributes and relationships of cross section tables and feature classes.

determining the amount of vertical exaggeration that has been applied in a given map requires probing into the coordinate system properties of the map and the data and applying some trigonometry on the standard parallel values.

Arc Hydro uses a different approach to handle vertical exaggeration. Cross section features are stored such that their geometries include the desired exaggeration. In other words, the cross section features are stored on disk "stretched out" in the $z$-direction. This workaround enables vertical exaggeration in ArcMap, while features such as XS2D_MajorGrid annotate the cross section with the true elevation values. The exaggeration amount is stored as an attribute of the section line feature defining the cross section, making it easy to visually inspect what amount of vertical exaggeration has been applied. Because the exaggeration is stored in feature geometries, the features are displayed with this exaggeration amount as soon as they are added to a map without requiring manipulation of the map coordinate system.

A disadvantage of this approach is that changing the vertical exaggeration requires editing features. Therefore, the Arc Hydro Groundwater Toolset includes tools for creating cross sections and managing properties such as vertical exaggeration. These tools can be run as a wizard or in ArcMap's geoprocessing environment. The tools are described in Section 5.

\section{Cross section tools and workflows}

The Arc Hydro Groundwater Toolset is a set of tools for working with Arc Hydro Groundwater features in ESRI's ArcGIS software. Included in the toolset is an extension called Subsurface Analyst for working with both two-dimensional cross sections and three-dimensional hydrogeologic features. Most of the tools relate to the creation of cross section data frames and cross section features, with other tools managing cross section properties such as vertical exaggeration. The most commonly used tools can be accessed as wizards and dialogs. However, the majority of tools are implemented as ArcGIS Geoprocessing tools, which means they can be chained together in sequences along with any other ArcGIS Geoprocessing tool (i.e., the suite of tools in ArcToolbox) to automate complex tasks and support a given organization's unique workflows.

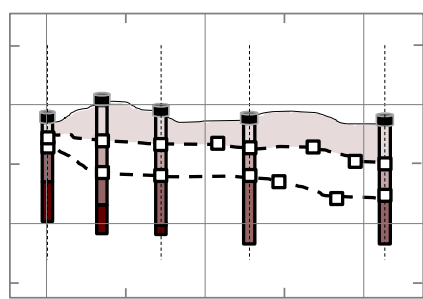

Fig. 4. Using borelines, major and minor grids, and panel dividers, cross section panels are digitized for each hydrogeologic unit. Figure shows one completed panel and a second panel in progress.

\subsection{Digitizing from borehole logs}

There are typically three workflows used to create twodimensional cross sections using Subsurface Analyst. In the first, the user selects a section line and pertinent boreholes in the map within ArcMap. A wizard opens, which prompts the user for certain cross section properties such as the desired vertical exaggeration, grid line spacing, and which features should be automatically created by reading from data sources such as a borehole log table and the feature class with pertinent boreholes. The wizard finishes by creating the desired cross section feature classes, populating them with data, and adding them to a new cross section data frame. At this point, the user would use features in the data frame such as borelines and panel dividers to manually digitize the panels for the cross section (Fig. 4). Additional features such as faults, geophysical logs, borehole construction data, surficial geology maps, topographic data, and other surfaces can be added with Subsurface Analyst to guide the digitization. Because these cross sections are stored as GIS features, the user can take advantage of standard GIS editing tools to streamline the creation of the panels.

\subsection{Digitizing from legacy cross section maps}

Many cross sections are readily available in printed form, and can be used to guide the creation of cross section panels in the GIS. In the second workflow, the user starts with a scanned image from a printed cross section and activates a wizard, which 


\section{a}

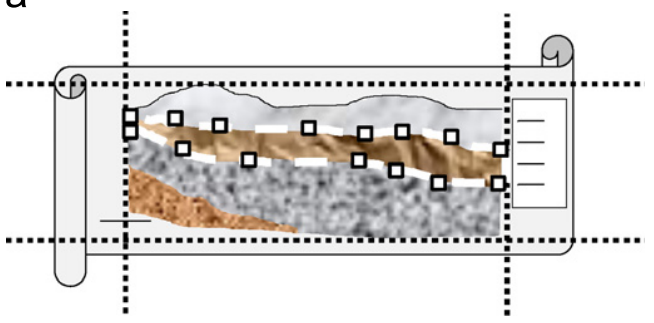

b

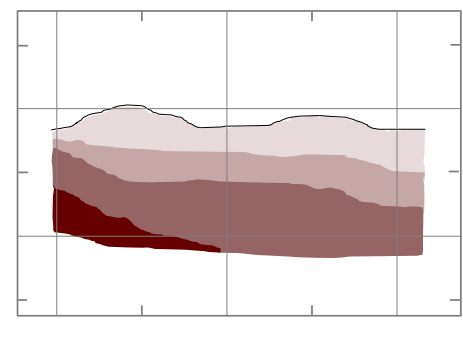

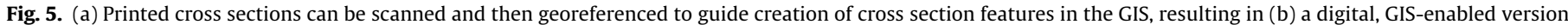
of a printed cross section.

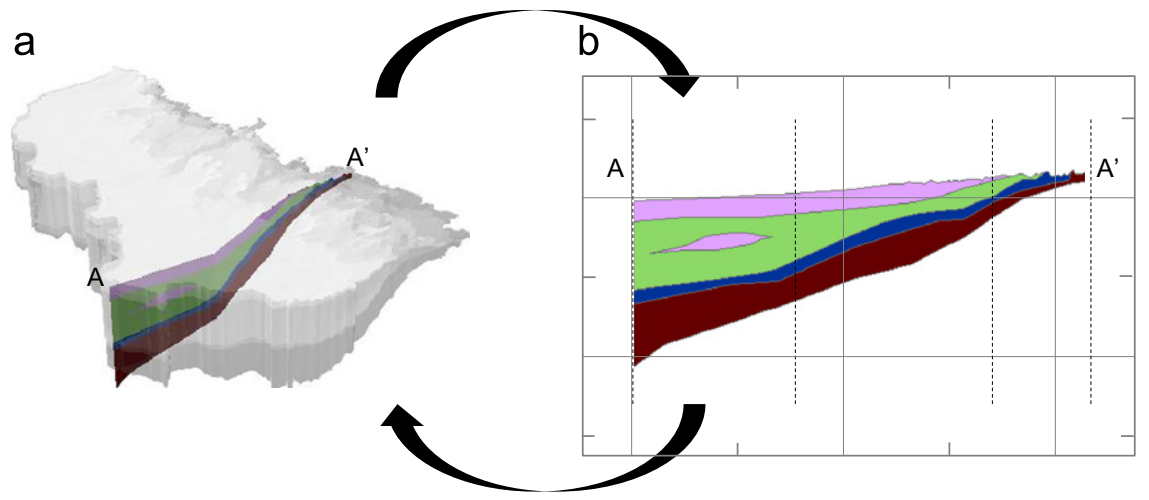

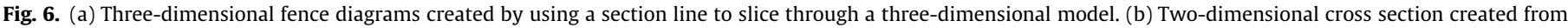
the three-dimensional fence diagram. Cross sections can be converted between two-dimensions and three-dimensions using the Arc Hydro Groundwater Toolset.

georeferences the image onto a cross section coordinate system for a given section line. The image is added to a new cross section data frame along with empty cross section feature classes. With the image as a backdrop on the screen, the user then traces out the cross section panels and other elements to create GIS features from the printed cross section (Fig. 5). This workflow enables the addition of "legacy" information captured in printed cross sections into new projects. For example, organizations can georeference existing cross sections from reports and geologic atlases and use information from these cross sections in the construction of a three-dimensional subsurface model.

\subsection{Interpolating from raster surfaces}

The third workflow is suited to cases when a wealth of borehole log data is available. The user interpolates surfaces representing the top of each hydrogeologic unit in ArcScene, or imports surfaces from a three-dimensional model. A section line is then used to create a vertical slice through the surfaces, resulting in a three-dimensional cross section or fence diagram. Subsurface analyst can convert back and forth between twodimensional and three-dimensional cross sections (Fig. 6), so now the user creates a two-dimensional cross section in ArcMap, and uses standard editing tools to tidy up the results of the interpolation.

Once a two-dimensional cross section has been created, it can be printed on the map layout just like any other map, converted to a fence diagram for three-dimensional display, or otherwise used to develop a three-dimensional subsurface model.

\section{Case study: Sacramento regional model}

A case study involving the Sacramento Valley in California illustrates an application of the Arc Hydro Groundwater data model and Toolset in ESRI's ArcGIS software. The application sets up the data framework for a project funded to develop a groundwater simulation model in support of a regional groundwater management plan. The details of the model are beyond the scope of this paper, and only the creation of cross section features is described here. The data for this example have been modified due to privacy concerns. The location of the study area is shown in Fig. 7.

The Sacramento Regional Model encompasses an area of approximately $3500 \mathrm{~km}^{2}$ near Roseville, California. Six stratigraphic units pertinent to the hydrogeology of the domain are identified and include Alluvium, Riverbank, Turlock Lake Laguna, Mehrten, Valley Springs, and Ione. Datasets used for creating cross sections include a GIS dataset of surficial soils representing the outcrops of the defined hydrogeologic units, and borehole locations with associated log data defining the vertical locations of hydrogeologic units along the boreholes. These data are loaded into the appropriate Arc Hydro Groundwater feature classes and tables in the GIS, and are supplemented with a digital elevation model of local topography.

The study area exhibits a downward slope from east to west with the Sierra Nevada mountain range marking the eastern boundary of the model domain. To get a sense of how the subsurface environment follows this trend, Sections $A-A^{\prime}$ and $B-B^{\prime}$ are drawn in the map and span the entire domain from west to east. Fig. 8 shows the area's six stratigraphic units and their surficial soil coverage, borehole locations, and the section lines identifying Section $A-A^{\prime}$ and Section $B-B^{\prime}$.

From the types of workflows described in Section 5, the first workflow is chosen here to build a cross section for Section $A-A^{\prime}$. Boreholes are selected within close proximity to the section line for display in the cross section. The section line is then selected in the map, which initiates the Cross Section Wizard. In the wizard, the appropriate GIS datasets representing borehole log data, borehole locations, and the XS2D catalog are selected, and the 


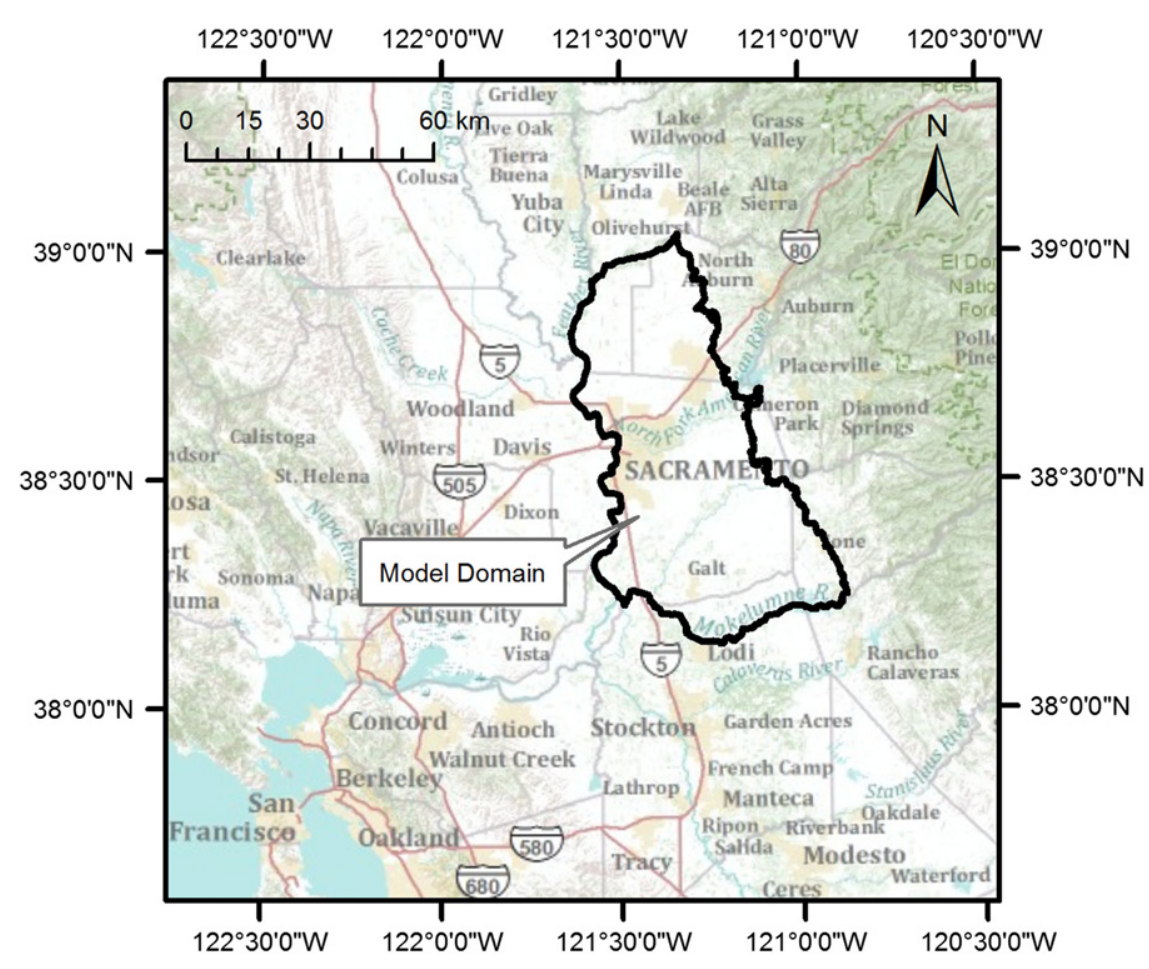

Fig. 7. Sacramento regional model domain.

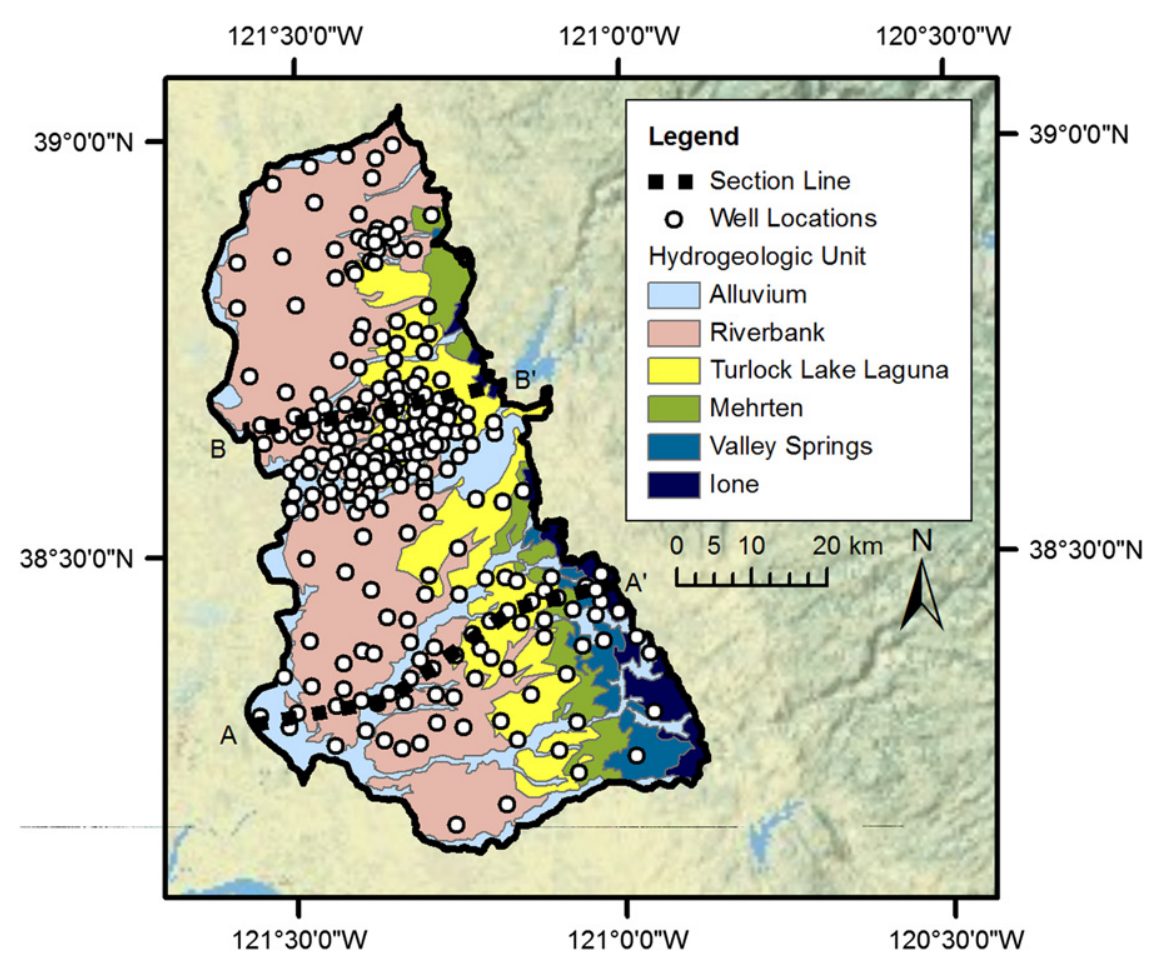

Fig. 8. Sections $A-A^{\prime}$ and $B-B^{\prime}$ traverse several hydrogeologic units in the study area.

wizard is instructed to create borelines, panel dividers, and grid lines in a new two-dimensional cross section. These features are automatically generated and placed in a new ArcMap data frame.

Using the Arc Hydro Groundwater Toolset, the digital elevation model, and the surficial soils coverage, linear features representing stratigraphic unit outcrops are added to the cross section and drawn at the proper land surface elevation. Features such as fault locations and the saltwater interface are also added using the Arc Hydro Groundwater Toolset. With these features in place, the cross section panels are manually digitized using standard ArcMap editing tools. Fig. 9 shows the resulting cross section features, including a lens on the western end of the cross section. Note that the lens is created for illustrative purposes only to demonstrate that such capabilities are possible in this framework.

With the cross section completed, a report is prepared highlighting the geology in the area. Because Cross Section $A-A^{\prime}$ is drawn within an ArcMap data frame, it can be easily arranged in the ArcMap print layout along with a map of the area and an 


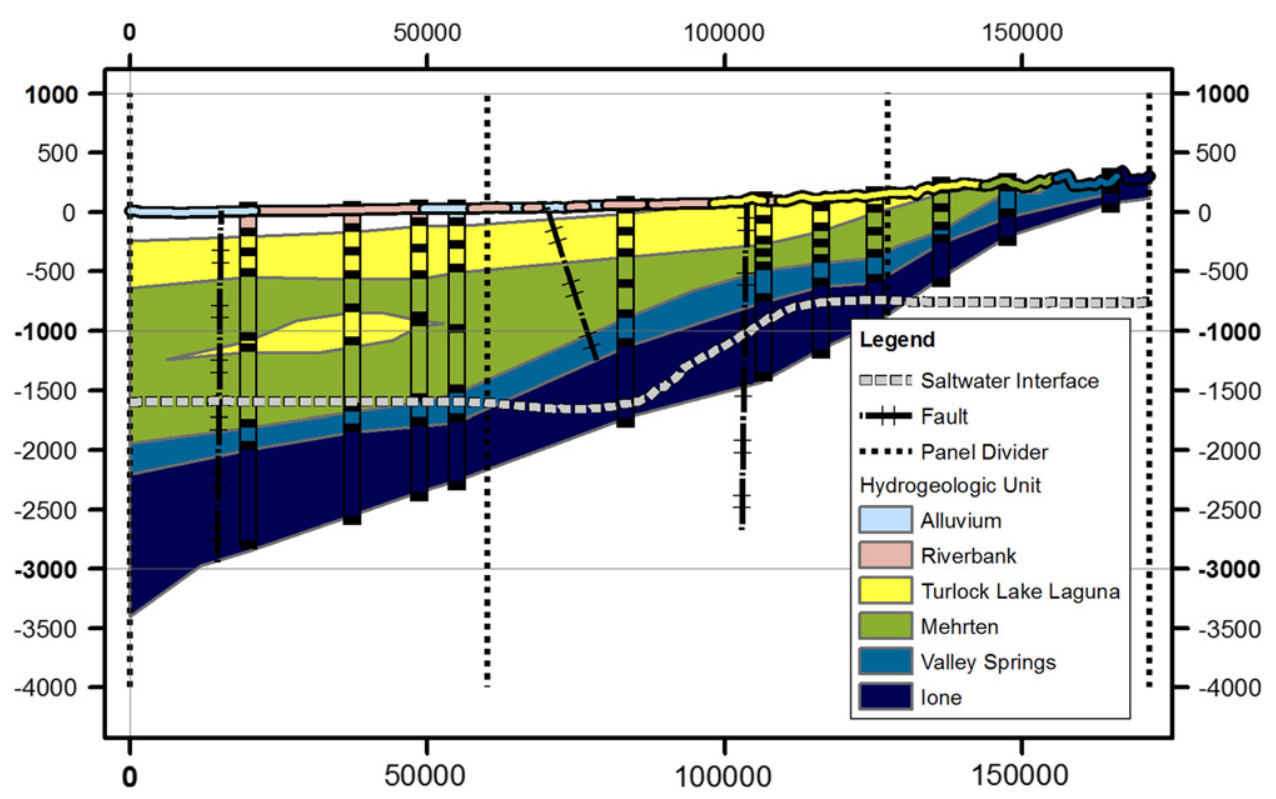

Fig. 9. Completed Section $A-A^{\prime}$.
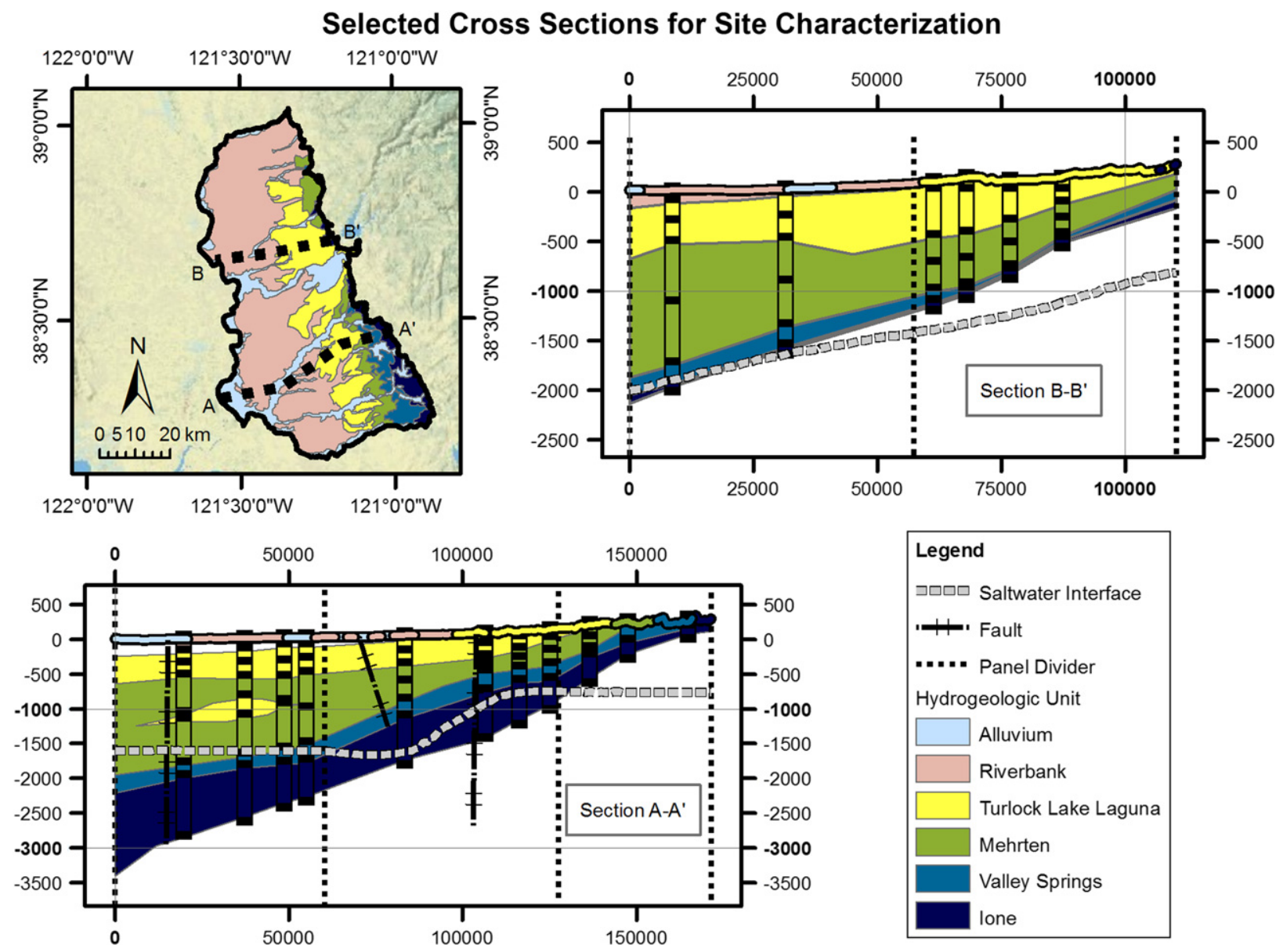

Fig. 10. Multiple cross sections can be arranged in a layout for printing.

explanation box. Because the cross section features are real GIS features, a legend showing the hydrogeologic units of interest can be created using standard ArcMap tools. For this report, a cross section for $B-B^{\prime}$ is also created in its own ArcMap data frame and added to the print layout. The resulting layout is shown in Fig. 10.
Further understanding of the study area can be obtained by visualizing subsurface features in a three-dimensional environment. Using Subsurface Analyst tools, the finished two-dimensional cross sections are converted to three-dimensional fence diagrams and displayed in ArcScene. Fig. 11 shows the 


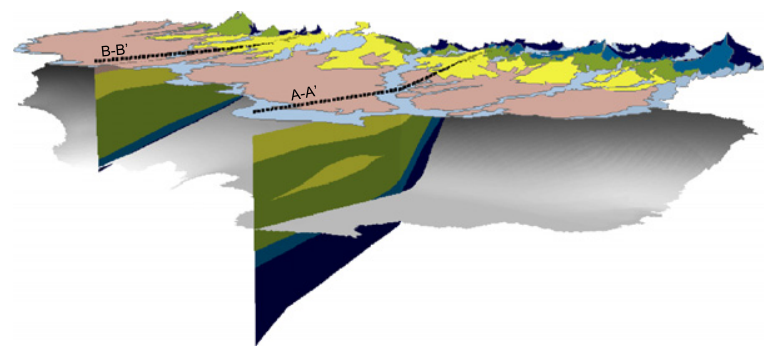

Fig. 11. Three-dimensional view of Sections $A-A^{\prime}$ and $B-B^{\prime}$ with other features related to site characterization.

three-dimensional cross sections with topography data and the saltwater interface.

\section{Conclusions}

This paper has illustrated how two-dimensional cross section features can be represented in a Geographic Information System using a component of the Arc Hydro Groundwater data model. The cross section features can be linked to other hydrologic features defined by Arc Hydro Groundwater and Arc Hydro for surface water. This work has also shown how cross section features can be created and managed using the Arc Hydro Groundwater Toolset. The tools support a variety of workflows for creating cross section features from tables of borehole data, existing printed cross sections, or three-dimensional models.

Despite these advances, there are still limitations inherent in trying to work with cross sections and their unique coordinate systems within standard GIS software. For example, due to vertical scaling in cross sections, the software cannot accurately produce certain GIS elements such as scale bars using out-of-thebox functionality, although features such as cross section grid lines can compensate for this shortcoming. Additionally, storing the vertical exaggeration of a cross section within cross section feature geometries is not ideal, but is necessary since mapping software designed for $x y$ representations of data typically cannot display an exaggeration in either the $x$ - or $y$-direction.
However, these limitations are mitigated by the ease of use of the Arc Hydro Groundwater Toolset to create and manage cross sections. The result is that geologists and engineers can add twodimensional cross sections to their list of assets when making geologic site characterizations using GIS.

\section{Acknowledgments}

The authors thank Derrick Whitehead and the city of Roseville, California, for the support and data associated with the Sacramento Regional Model featured in this article.

\section{References}

A-Prime Software, 2008. CrossView. Manhattan, KS, 〈http://www.aprimesoft ware.com/ $>$ (accessed February 2, 2011).

Herbert, M.J., Jones, C.B., Tudhope, D.S., 1995. Three-dimensional reconstruction of geoscientific objects from serial sections. Visual Computer 11 (7), 343-359.

Huber, B., 2007. Discussion Forum Response. Archived ArcGIS Desktop Discussion Forums; Projections, Projection Engine Forum; Apply Stretch to $Y$ Axis? $\langle$ http://forums.esri.com/Thread.asp?c=93\&f=984\&t=190243 $>$ (accessed May 11, 2011).

Kaufmann, O., Martin, T., 2008. 3D geological modelling from boreholes, crosssections and geological maps, application over former natural gas storages in coal mines. Computers \& Geosciences 34 (3), 278-290.

Lemon, A.M., Jones, N.L., 2003. Building solid models from boreholes and userdefined cross-sections. Computers \& Geosciences 29, 547-555.

Maidment, D.R. (Ed.), 2002. Arc Hydro: GIS for Water Resources. ESRI Press, Redlands, CA 220 pp.

Ming, J., Pan, M., Qu, H., Ge, Z., 2010. GSIS: a 3D geological multi-body modeling system from netty cross-sections with topology. Computers \& Geosciences 36 (6), 756-767.

RockWare, 2010. RockWare GIS Link 2, RockWare-Earth Science and GIS Software, Golden, CO, 〈http://www.rockware.com/product/overview.php?id= $166>$ (accessed February 2, 2011).

Strassberg, G., Maidment, D.R., Jones, N.L., 2007. A geographic data model for representing ground water systems. Ground Water 45 (4), 515-518.

Strassberg, G., Jones, N.L., Maidment, D.R., 2011. Arc Hydro Groundwater: GIS for Hydrogeology. ESRI Press, Redlands, CA $250 \mathrm{pp}$

Thoms, E., 2008. Geologic Cross Section Tool. United States Geological Survey, Anchorage, AK, 〈http://arcscripts.esri.com/details.asp?dbid=15530〉 (accessed February 2, 2011)

Tipper, J.C., 1976. Study of geological objects in 3 dimensions by computerized reconstruction of serial sections. Journal of Geology 84 (4), 476-484. 